\title{
Statin-Associated Myopathy: From Genetic Predisposition to Clinical Management
}

\author{
M. VRABLIK ${ }^{1}$, L. ZLATOHLAVEK ${ }^{1}$, T. STULC ${ }^{1}$, V. ADAMKOVA ${ }^{2}$, M. PRUSIKOVA ${ }^{1}$, \\ L. SCHWARZOVA ${ }^{1}$, J. A. HUBACEK ${ }^{3}$, R. CESKA ${ }^{1}$
}

${ }^{1}$ Third Department of Internal Medicine, First Faculty of Medicine, Charles University, Prague, Czech Republic, ${ }^{2}$ Department of Preventive Cardiology, Institute for Clinical and Experimental Medicine, Prague, Czech Republic, ${ }^{3}$ Center for Experimental Medicine, Institute for Clinical and Experimental Medicine, Prague, Czech Republic

Received July 9, 2014

Accepted July 22, 2014

\section{Summary}

Statin-associated myopathy (SAM) represents a broad spectrum of disorders from insignificant myalgia to fatal rhabdomyolysis. Its frequency ranges from $1-5 \%$ in clinical trials to $15-20 \%$ in everyday clinical practice. To a large extent, these variations can be explained by the definition used. Thus, we propose a scoring system to classify statin-induced myopathy according to clinical and biochemical criteria as 1) possible, 2) probable or 3) definite. The etiology of this disorder remains poorly understood. Most probably, an underlying genetic cause is necessary for overt SAM to develop. Variants in a few gene groups that encode proteins involved in: i) statin metabolism and distribution (e.g. membrane transporters and enzymes; OATP1B1, ABCA1, MRP, CYP3A4), ii) coenzyme Q10 production (e.g. COQ10A and B), iii) energy metabolism of muscle tissue (e.g. PYGM, GAA, CPT2) and several others have been proposed as candidates which can predispose to SAM. Pharmacological properties of individual statin molecules (e.g. lipophilicity, excretion pathways) and patients characteristics influence the likelihood of SAM development. This review summarizes current data as well as our own results.

\section{Key words}

Statins • Statin associated myopathy • Definition • Risk score • Genetics

\section{Corresponding author}

M. Vrablik, Third Department of Internal Medicine, General University Hospital, U Nemocnice 1, 12808 Prague 2, Czech Republic. Fax: +420 224966 677. E-mail: michal.vrablik@vfn.cz

\section{Introduction}

Statins are an extremely powerful and wellestablished class of drugs. Numerous experimental and clinical data support their use for a wide range of indications and clinical situations. Most patients treated with statins tolerate statins without difficulty; even longterm treatment has not been associated with deleterious impact to any particular organ system. Given the increasing number of indications for statins and the growing number of users, more attention has been drawn to the side effects of statin therapy. Contrary to randomized clinical trials, where the occurrence of adverse reactions ranges between 1 and $5 \%$, actual clinical experience, as reported in the literature, suggests that the number of undesirable effects stemming from statin use is much higher (15-20\%).

Statin-associated myopathy (SAM) represents one of the most significant and frequent side effects of these drugs, and it is estimated that up to two thirds of all statin-related side effects involve muscle tissue (Raju et al. 2013). Observational studies suggest that $10-15 \%$ of statin users develop some type of muscle problem (Abd and Jacobson 2011). It is estimated that almost $30 \%$ of statin discontinuations occur within the first year of treatment and are most likely due to adverse side effects (Kamal-Bahl et al. 2007). Despite the literature being relatively rich on this topic, uncertainty continues and ranges from its definition and underlying 
mechanisms, to treatment options.

\section{Definition of statin-associated myopathy}

A universally accepted definition of SAM does not exist. Typically, SAM is understood to be any muscular symptoms occurring during statin treatment (with or without elevations of creatine kinase in the serum) that resolve on treatment interruption. However, attempts at an unambiguous definition have been problematic for several reasons. First, SAM has a highly variable clinical presentation ranging from muscle tenderness, cramping and muscle aches to weakness and, the far more serious, rhabdomyolysis. Both patients and physicians often ascribe arthralgia or common muscle tiredness following exercise to statins. Second, all of these symptoms are non-specific and a single symptom differentiating SAM from common myalgia accompanying other diseases (e.g. viral or bacterial infections, rheumatoid and orthopedic diseases, endocrine disorders, etc.) has not been identified. Third, symptoms of SAM are subjective in nature and there is not a reliable marker that proves the diagnosis, particularly when referring to milder forms of the disorder. Fourth, the lack of a uniform definition of SAM leads to misclassification of some cases, which hampers evaluation and comparison with those cases presented in the literature.

Therefore, a scoring system classifying the probability of SAM based on patients' history, clinical picture and laboratory markers would be useful. Table 1 summarizes the clinical and biochemical criteria of SAM.

Table 1. Clinical and laboratory criteria of SAM (StatinAssociated Myopathy).

\section{Characteristics}

\section{Points}

$\begin{array}{ll}\text { Typical clinical picture of muscle aches } & 1 \\ \text { (symmetrical, dull pain or tenderness) } & \\ \text { Occurrence within } 4 \text { weeks from the } & 1 \\ \text { initiation therapy } & 1 \\ \text { Resolving with the interruption of therapy } & 1 \\ \text { Family history of SAM } & 2 \\ \text { Elevations of CK }>5 x U L N & 2 \\ \text { Positive re-challenge test } & 5 \\ \text { Confirmed rhabdomyolysis } & 5 \\ \text { Histological confirmation of SAM } & \end{array}$

Possible SAM (1-2 points), Probable SAM (3-4 points), Definite SAM (5 or more points). CK - creatin kinase, ULN - upper limit of normal.
Based on the above-outlined criteria, patients can be classified as having possible SAM (1-2 points), probable SAM (3-4 points), or definite SAM (5 or more points). Such classification might aid in the differentiation of common myalgias from those induced or worsened by statin therapy. Additionally, it could be used to enhance the stratification of the severity of SAM in individual cases.

\section{Mechanisms of statin-associated myopathy}

As in many conditions, the exact mechanism of SAM development remains unknown and, as with other conditions, the etiology of the disorder is multifactorial. Putative causal mechanisms include but are not limited to the following (adapted according to Ghatak et al. 2010):

- Decreased intracellular concentrations of cholesterol

- Reduced production of coenzyme Q10 and related ubiquinones

- Decreased production of prenylated proteins

- Increased uptake of cholesterol from the extracellular space

- Increased uptake of phytosterols

- Disruption of calcium metabolism in myocytes

- Decreased renewal of damaged muscle cells via the ubiquitin pathway

- Inhibition of selenoprotein synthesis

- Genetic factors

- Unmasking of pre-existing muscular disorders

Obviously, other mechanisms could play a role in the development of SAM in any given particular individual. Therefore, it may be difficult, or perhaps even impossible, to identify the most significant contributor to the development of SAM. However, there are conditions and patient characteristics which typically increase susceptibility to all adverse effects of statins, including SAM; these include higher age, female gender, concomitant medication usage (see Table 2A), presence of comorbidities (see Table 2B) and a high level of physical activity.

High levels of physical activity, in particular, warrants attention, since increased physical fitness is generally recommended as a means to reduce the risk of cardiovascular and other diseases. Indeed, a relationship between physical activity, statin use and increased risk of muscular symptoms has been described in some (Parker et al. 2012, Semple 2012, Mikus et al. 2013), but not all (Newman 2006) studies. Interestingly, one of the rare, well-designed, randomized, double-blind trials, which 
tested whether statin administration reduces muscle strength and adversely impacts overall physical performance in otherwise healthy individuals, failed to show any deleterious effects relative to these parameters. Nevertheless, even this trial documented an increased frequency of muscle complaints and elevation of creatine kinase levels in those allocated to active statin treatment compared to placebo (Parker et al. 2013). However, to date, this issue has not been examined in any clinical studies having sufficient power (Krishnan and Thompson 2010).

Table 2. A. Most important inhibitors of cytochrome $\mathrm{P} 450$ systems metabolising statins (according to Dosedel et al. 2011).

\begin{tabular}{l|l}
\hline $\begin{array}{l}\text { Isoenzyme CYP3A4 } \\
\text { (lovastatin, atorvastatin, } \\
\text { simvastatin) }\end{array}$ & $\begin{array}{l}\text { Isoensyme CYP2C9 } \\
\text { (rosuvastatin, fluvastatin) }\end{array}$ \\
\hline $\begin{array}{l}\text { Protease inhibitors } \\
\text { (indinavir, ritonavir etc.) }\end{array}$ & Fluconazole \\
\hline $\begin{array}{l}\text { Macrolides } \\
\text { (clarithromycin) }\end{array}$ & Amiodarone \\
\hline $\begin{array}{l}\text { Azole antifungal drugs } \\
\text { (ketoconazole, } \\
\text { fluconazole) }\end{array}$ & Fenofibrate \\
\hline Cyclosporin & \\
\hline Diltiazem & Fluvoxamin \\
\hline Verapamil & Sertralin \\
\hline Amiodarone & Vorikonazole \\
\hline Grapefruit juice & \\
\hline
\end{tabular}

Strong inhibition: results in at least $80 \%$ reduction of statin clearance; Moderate inhibition: results in $50-80 \%$ reduction of statin clearance.

Table 2. B. Typical comorbidities predisposing to statinassociated myopathy.

\begin{tabular}{ll}
\hline Endocrine & $\begin{array}{l}\text { Diabetes mellitus } \\
\text { Thyroid disorders } \\
\text { Cushing's syndrome } \\
\end{array}$ \\
& Vitamin D deficiency \\
\hline Neurological & $\begin{array}{l}\text { Myasthenia gravis } \\
\text { Primary myopathy }\end{array}$ \\
\hline Chronic kidney & Association with GFR \\
disease & reduction \\
\hline Chronic liver disease & Viral or autoimmune hepatitis \\
\hline Rheumatic diseases & Systemic lupus erythematosus \\
& Polymyalgia rheumatica \\
& Rheumatoid arthritis \\
\hline Drug addiction & e.g. alcohol, cocaine abuse \\
\hline
\end{tabular}

\section{Genetic factors predisposing to SAM}

As with many other medical conditions, it has been suggested that statin-related muscular side effects have an underlying genetic background that determines the susceptibility to development. However, it is difficult to estimate the proportion of genetic and non-genetic (environmental) factors which lead to the development of SAM.

The most important genetic determinants of SAM are summarized in Table 3.

These include variants within the genes responsible for: 1) statin concentrations in the plasma, although this does not seem to be the best predictor of the risk of undesirable statin side effects, 2) muscle vascularization, 3) regulation of intracellular statin concentrations in the myocytes, and 4) the development of rare disorders linked to muscle tissue energy metabolism, as well as several other conditions.

The first studies searching for variants associated with SAM utilized the candidate gene approach (primarily using a case-control study design). However, the application of this method is problematic given that the exact molecular mechanisms of SAM remain unclear. Thus, research has focused on gene variants within the putative metabolic pathways, e.g. fatty acid oxidation, isoprenoid production with the resulting decreased bioavailability of coenzyme Q, etc. (reviewed by Abd and Jacobson 2011). The studies focused on variants within genes having known biological functions, primarily statin transporters or statin metabolizing enzymes (reviewed by Hubacek 2014, Needham and Mastaglia 2014). Variants in genes involved in (i) lipid metabolism [e.g. hydroxymethylglutaryl coenzyme A $(H M G-C o A)]$, (ii) reductase and (iii) apolipoprotein $\mathrm{E}$ (APOE) genes which also play a role in statin treatment efficacy, have been less frequently implicated in susceptibility to SAM. For example, the reduced treatment efficacy associated with the APOE4 allele could reflect an undetected higher rate of treatment discontinuation due to the increased prevalence of SAM and other adverse effects of statins (Hubacek and Vrablik 2011).

Variants within the genes coding for the cytochrome P450 (CYP) enzyme superfamily (http://cypalleles.ki.se) are among the most widely studied in the context of SAM. In particular, variants within the genes for CYP2D6 (coumarin 7 hydroxylase), CYP3A4 (glucocorticoid inducible p450) and MDR-1 
(multidrug resistance 1, ABCB1 transporter) have been proposed as being associated with SAM (Frudakis et al. 2007, Zuccaro et al. 2007, Voora et al. 2009). The limitations of these studies include heterogeneous populations, small sample sizes and the absence of confirmatory works. Thus, no definite conclusions can be drawn at this moment regarding the relative importance of these gene variations in the development of SAM.

Table 3. Genes with potential to induce SAM.

\begin{tabular}{|c|c|c|}
\hline $\begin{array}{l}\text { Genetic variation } \\
\text { accounting for: }\end{array}$ & Factors & Genes \\
\hline Statin plasma & Transporters & $O A T P 1 B 1$ \\
\hline \multirow[t]{9}{*}{ concentration } & & OATP1B3 \\
\hline & & $O A T P 2 B 1$ \\
\hline & & $A B C B 1$ \\
\hline & & $A B C G 2$ \\
\hline & Enzymes & CYР $3 A 4$ \\
\hline & & CYP3A5 \\
\hline & & $C Y P 2 C 8$ \\
\hline & & $C Y P 1 A 2$ \\
\hline & & CYP2 \\
\hline Muscle tissue & & $A G T R 1$ \\
\hline vascularization & & NOS 3 \\
\hline Intracellular statin & & $O A T P 2 B 1$ \\
\hline concentration & & $M R P 1,4,5$ \\
\hline Rare disorders of & & PYGM \\
\hline muscle tissue & & $G A A$ \\
\hline energy metabolism & & CPT2 \\
\hline $\begin{array}{l}\text { Mitochondrial } \\
\text { myopathies }\end{array}$ & Mitochondrial & \\
\hline Variability in & & COQ10A \\
\hline coenzyme $Q 10$ & & $C O Q 10 B$ \\
\hline \multicolumn{3}{|l|}{ production } \\
\hline Muscular & & $D M D$ (dystrophin) \\
\hline \multirow[t]{3}{*}{ dystrophy } & & MYOT (myotilin) \\
\hline & & $L M N A$ (lamin) \\
\hline & & $C A V 3$ (caveolin) \\
\hline Calcium & & $R Y R$ (ryanodine \\
\hline homeostasis & & receptors) \\
\hline \multirow[t]{4}{*}{ factors } & & $A T P 1 A 1$ \\
\hline & & ATP1A2 \\
\hline & & $A T P 1 B 1$ \\
\hline & & (NaKATPase) \\
\hline
\end{tabular}

Another plausible genetic factor linked to SAM susceptibility is a variation in the CoQ2 gene encoding for coenzyme Q10. Coenzyme Q10 (CoQ10) is one of the end products of the mevalonate pathway and statins lead to its depletion in a dose-dependent manner. CoQ10 deficiency has been shown to be associated with an elevated risk of myopathy (Emmanuele et al. 2012). Two variants within the CoQ2 gene have been shown to double the risk of statin intolerance ( $\mathrm{Oh}$ et al. 2008). Unfortunately, these results remain to be replicated.

Rare variants within the genes for CYP3A4 and $\mathrm{ABCB} 1$ have been found to be overrepresented in subjects requiring down-titration of statins and/or switching from atorvastatin to an alternative, thus indirectly pointing to their possible association with SAM (Becker et al. 2010).

\section{GWA studies in the identification of gene variants predisposing to SAM}

Genome-wide association studies (GWAs) were first used nearly ten years ago and this approach has found utility in a number of research areas (Leiserson et al. 2013, Robinson et al. 2014). Using an extensive analysis of hundreds of thousands of single-nucleotide polymorphisms with a frequency of at least $5 \%$ in the population, genetic risk factors for different diseases have been identified.

The need to gather very large numbers of individuals with relatively low frequencies of SAM, as well as the heterogeneity of studies on the topic, hampers the utility of the GWA approach in the attempt to identify genetic causes of statin-associated myopathy. To date, there have only been two GWA studies addressing this topic. The Search Collaborative Group (2008) identified SNP rs4149056 (c.521T $\rightarrow$ C) within the SLCO1B1 gene as being associated with an almost five times higher risk of myopathy (per minor allele) in patients taking high doses of simvastatin. SLCO1B1 codes for the organic anion-transporting polypeptide 1B1 (OATP1B1), which is a transmembrane transporter expressed on human hepatocytes. This transporter not only mediates the hepatic uptake of statins, it performs the same function for many endogenous compounds and xenobiotics, as well (Niemi et al. 2011). Tagging the rs4149056 variant also significantly affects cholesterol synthesis, although the exact mechanism is not known (Pasanen et al. 2008).

OATP1B1 mediates the transmembrane traffic of all statins; however, it has a different relative impact 
on the average concentration of individual statin molecules. After the administration of a single statin dose, the area under the curve (AUC) in rare SLCO1B1 variant carriers increases most in simva- and atorvastatin, while prava- and rosuvastatin concentrations increase only slightly, while fluvastatin concentrations do not differ significantly. This might explain why the original SEARCH results have been confirmed by some (Donnelly et al. 2011, Carr et al. 2013), but no all (Voora et al. 2009, Brunham et al. 2012, Danik et al. 2013) subsequent studies.

A recent summary (Stewart 2013) of those studies published to date suggested that this test would have had a better clinical utility for detecting individuals (TT homozygotes) tolerant to high doses of statins, since $\mathrm{CC}$ carriers (minor allele homozygotes) not only have an increased risk of SAM, but also often show a lower response to statin treatment. This relates to the proven impact of the rs4149056 (c.521T $\rightarrow$ C) variant on plasma levels of statins (Niemi et al. 2006, Pasanen et al. 2006, Pasanen et al. 2007), which may be gender-specific (Hubacek et al. 2012).

Finally, not only common polymorphisms, but also rare mutations within this gene, could be associated with statin-associated myopathy (Furihata et al. 2009).

The second GWA study (Marciante et al. 2011) examined individuals suffering from rhabdomyolysis following treatment with cerivastatin, which was withdrawn from the market in 2001 due to serious adverse effects (Griffin 2001). While variants within the above-mentioned SLCO1B1 transporter gene have been confirmed to positively associate with the risk of SAM, a variant within the ryanodine receptor 2 gene (RYR-2) was shown to significantly lower the risk of SAM. However, it is not known whether this protective effect can be confirmed in patients treated with other statins, since this gene polymorphism has not yet been examined in patients with myalgia/myopathy being treated with different statins.

\section{Clinical management of SAM}

The clinical approach to the management of statin-associated myopathy has undergone a re-evaluation and expert societies have published clinical guidelines for its identification and management (McKenney et al. 2006, Catapano et al. 2011). The American National Lipid Association (NLA) has summarized the approach to patients developing SAM as follows.

\section{Patient monitoring}

Patient monitoring includes following points:

1. Obtain baseline CK levels in high-risk patients (renal dysfunction, liver disease, polypharmacy).

2. Routine CK levels in asymptomatic patients are not recommended.

3. Consider CK levels in patients with musclerelated symptoms.

4. Rule out other etiologies in other symptomatic patients, or those with elevated CK levels (hypothyroidism, trauma, seizures, infection, strenuous physical activity).

5. Exacerbating factors should be considered (concomitant medications and herbal remedies).

\section{Management of muscle symptoms}

Management of muscle symptoms should be perfomed according these rules:

1. If intolerable muscle symptoms develop, discontinue the statin regardless of $\mathrm{CK}$ levels and rechallenge only after the patient becomes asymptomatic.

2. If muscle symptoms are tolerable and $\mathrm{CK}$ elevation is mild ( $<10$ times the upper limit of normal), statin therapy can be continued and muscle symptoms can be used as a guide to cease or continue treatment.

3. If muscle symptoms are tolerable and $\mathrm{CK}$ elevation is moderate to severe, discontinue statin therapy and weigh the risks and benefits.

4. If muscle symptoms are tolerable and CK elevation is associated with elevated creatinine or the need for intravenous hydration, discontinue therapy.

The discontinuation of statin therapy remains the first approach in the management of SAM, in conjunction with a creatine kinase assessment. Measurement of myoglobin as another marker of statin induced muscle injury is not recommended due to its short half-life in the plasma as well as tight connection of its levels to renal function. These factors decrease the utility of myoglobin as a marker of SAM while it remains an important parameter in the diagnosis and monitoring of rhabdomyolysis (Premru et al. 2013). A search for potentially precipitating factors and their treatment (concomitant medications and comorbidities; see Tables 2A and 2B) should follow.

Rhabdomyolysis requires in-hospital treatment which includes intensive intravenous hydration, urinary alkalization and close monitoring to prevent acute renal 
failure due to tubular obstruction from myoglobin precipitates.

The role of coenzyme Q10 administration has attracted much attention; however, results from (typically uncontrolled) published studies have, so far, yielded variable results. Therefore, the routine administration of such agents in SAM patients is not yet recommended (McKenney et al. 2006, Young et al. 2007, Zlatohlavek et al. 2012).

Vitamin D deficiency can lead to an increased susceptibility to the development of SAM (Eisen et al. 2014). Therefore, it is not surprising that the clinical utility of vitamin D supplementation in SAM patients has been tested in clinical studies. Some patients have shown better tolerance of statins during vitamin D supplementation (Glueck et al. 2011). However, the data remains limited and, therefore, no firm conclusion can be drawn (Gupta and Thomson 2011).

Most importantly, should the symptoms of SAM disappear and the precipitating factors be removed, it is worth trying at least two different statins in an effort to find a statin which the patient can tolerate. The introduction of a new statin should be titrated and closely monitored, starting with the lowest initial dosage. In a study by Hansen and colleagues, $43 \%$ of patients with symptomatic SAM were able to tolerate an alternative statin (Hansen et al. 2005). Testing of several different statins should be performed before a patient is labelled as statin-intolerant and switched to a non-statin lipidlowering treatment.

\section{Conclusions}

Statin-associated myopathy represents a growing problem given the increasing use of statins in various population groups. Genetic background increases the susceptibility of its development, particularly in subjects with additional risks. Treatment of SAM involves a careful assessment of all potential precipitating SAM factors and their elimination, together with statin cessation. Switching a patient to an alternative statin should be considered; additionally, vitamin D supplementation might also improve tolerance.

\section{Conflict of Interest}

There is no conflict of interest.

\section{Acknowledgements}

This work was supported by project No. NS 11307-5. JAH is supported by project $\mathrm{MH} \mathrm{CZ} \mathrm{-} \mathrm{DRO} \mathrm{(Institute}$ for Clinical and Experimental Medicine - IKEM, IN 00023001).

\section{References}

ABD TT, JACOBSON TA: Statin-induced myopathy: a review and update. Expert Opin Drug Saf 10: 373-387, 2011. BECKER ML, VISSER LE, VAN SCHAIK RH, HOFMAN A, UITTERLINDEN AG, STRICKER BH: Influence of genetic variation in CYP3A4 and ABCB1 on dose decrease or switching during simvastatin and atorvastatin therapy. Pharmacoepidemiol Drug Saf 19: 75-81, 2010.

BRUNHAM LR, LANSBERG PJ, ZHANG L, MIAO F, CARTER C, HOVINGH GK, VISSCHER H, JUKEMA JW, STALENHOEF AF, ROSS CJ, CARLETON BC, KASTELEIN JJ, HAYDEN MR: Differential effect of the rs4149056 variant in SLCO1B1 on myopathy associated with simvastatin and atorvastatin. Pharmacogenomics J 12: 233-237, 2012.

CATAPANO AL, REINER Z, DE BACKER G, GRAHAM I, TASKINEN MR, WIKLUND O, AGEWALL S, ALEGRIA E, CHAPMAN M, DURRINGTON P, ERDINE S, HALCOX J, HOBBS R, KJEKSHUS J, FILARDI PP, RICCARDI G, STOREY RF, WOOD D; EUROPEAN SOCIETY OF CARDIOLOGY (ESC); EUROPEAN ATHEROSCLEROSIS SOCIETY (EAS): ESC/EAS Guidelines for the management of dyslipidaemias. Atherosclerosis 217: 3-46, 2011.

CARR DF, O'MEARA H, JORGENSEN AL, CAMPBELL J, HOBBS M, MCCANN G, VAN STAA T, PIRMOHAMED M: SLCO1B1 genetic variant associated with statin-induced myopathy: a proof-of-concept study using the clinical practice research datalink. Clin Pharmacol Ther 94: 695-701, 2013.

DANIK JS, CHASMAN DI, MACFADYEN JG, NYBERG F, BARRATT BJ, RIDKER PM: Lack of association between SLCO1B1 polymorphisms and clinical myalgia following rosuvastatin therapy. Am Heart J 165: 1008-1014, 2013. 
DONNELLY LA, DONEY AS, TAVENDALE R, LANG CC, PEARSON ER, COLHOUN HM, MCCARTHY MI, HATTERSLEY AT, MORRIS AD, PALMER CN: Common nonsynonymous substitutions in SLCO1B1 predispose to statin intolerance in routinely treated individuals with type 2 diabetes: a go-DARTS study. Clin Pharmacol Ther 89: 210-216, 2011.

DOSEDEL M, MALY J, VLCEK J: Drug interactions with statins and their clinical severity and management. Remedia 21: 392-397, 2011.

EISEN A, LEV E, IAKOBISHVILLI Z, PORTER A, BROSH D, HASDAI D, MAGER A: Low plasma vitamin D levels and muscle-related adverse effects in statin users. Isr Med Assoc J 16: 42-45, 2014.

EMMANUELE V, LÓPEZ LC, BERARDO A, NAINI A, TADESSE S, WEN B, D'AGOSTINO E, SOLOMON M, DIMAURO S, QUINZII C, HIRANO M: Heterogeneity of coenzyme Q10 deficiency: patient study and literature review. Arch Neurol 69: 978-983, 2012.

FRUDAKIS TN, THOMAS MJ, GINJUPALLI SN, HANDELIN B, GABRIEL R, GOMEZ HJ: CYP2D6*4 polymorphism is associated with statin-induced muscle effects. Pharmacogenet Genomics 17: 695-707, 2007.

FURIHATA T, SATOH N, OHISHI T, UGAJIN M, KAMEYAMA Y, MORIMOTO K, MATSUMOTO S, YAMASHITA K, KOBAYASHI K, CHIBA K: Functional analysis of a mutation in the SLCO1B1 gene (c.1628T $>$ G) identified in a Japanese patient with pravastatin-induced myopathy. Pharmacogenomics $J$ 9: 185-193, 2009.

GHATAK A, FAHEEM O, THOMPSON PD: The genetics of statin-induced myopathy. Atherosclerosis 210: 337-343, 2010.

GLUECK CJ, BUDHANI SB, MASINENI SS, ABUCHAIBE C, KHAN N, WANG P, GOLDENBERG N: Vitamin D deficiency, myositis-myalgia, and reversible statin intolerance. Curr Med Res Opin 27: 1683-1690, 2011.

GRIFFIN JP: The withdrawal of Baycol (cerivastatin). Adverse Drug React Toxicol Rev 20: 177-180, 2001.

GUPTA A, THOMPSON PD: The relationship of vitamin D deficiency to statin myopathy. Atherosclerosis 215: 23-29, 2011.

HANSEN KE, HILDEBRAND JP, FERGUSON EE, STEIN JH: Outcomes in 45 patients with statin-associated myopathy. Ann Intern Med 165: 2671-2676, 2005.

HUBACEK JA: Drug metabolising enzyme polymorphisms in Middle- and Eastern-European Slavic populations. Drug Metabol Drug Interact 29: 29-36, 2014.

HUBACEK JA, VRABLIK M: Effect of apolipoprotein E polymorphism on statin-induced decreases in plasma lipids and cardiovascular events. Drug Metabol Drug Interact 26: 13-20, 2011.

HUBACEK JA, DLOUHA D, ADÁMKOVA V, LANSKA V, CESKA R, VRABLIK M: Possible gene-gender interaction between the SLCO1B1 polymorphism and statin treatment efficacy. Neuro Endocrinol Lett 33 (Suppl 2): 22-25, 2012.

KAMAL-BAHL SJ, BURKE T, WATSON D, WENTWORTH C: Discontinuation of lipid modifying drugs among commercially insured United States patients in recent clinical practice. Am J Cardiol 99: 530-534, 2007.

KRISHNAN GM, THOMPSON PD: The effects of statins on skeletal muscle strength and exercise performance. Curr Opin Lipidol 21: 324-328, 2010.

LEISERSON MD, ELDRIDGE JV, RAMACHANDRAN S, RAPHAEL BJ: Network analysis of GWAS data. Curr Opin Genet Dev 23: 602-610, 2013.

MARCIANTE KD, DURDA JP, HECKBERT SR, LUMLEY T, RICE K, MCKNIGHT B, TOTAH RA, TAMRAZ B, KROETZ DL, FUKUSHIMA H, KASPERA R, BIS JC, GLAZER NL, LI G, AUSTIN TR, TAYLOR KD, ROTTER JI, JAQUISH CE, KWOK PY, TRACY RP, PSATY BM: Cerivastatin, genetic variants, and the risk of rhabdomyolysis. Pharmacogenet Genomics 21: 280-288, 2011.

MCKENNEY JM, DAVIDSON MH, JACOBSON TA, JACOBSON TA, GUYTON JR: Final conclusions and recommendations of the National Lipid Association Statin Safety Assessment Task Force. Am J Cardiol 97: 89C-94C, 2006.

MIKUS CR, BOYLE LJ, BORENGASSER SJ, OBERLIN DJ, NAPLES SP, FLETCHER J, MEERS GM, RUEBEL M, LAUGHLIN MH, DELLSPERGER KC, FADEL PJ, THYFAULT JP: Simvastatin impairs exercise training adaptations. J Am Coll Cardiol 62: 709-714, 2013. 
NEEDHAM M, MASTAGLIA FL: Statin myotoxicity: a review of genetic susceptibility factors. Neuromuscul Disord 24: 4-15, 2014.

NEWMAN C, TSAI J, SZAREK M, LUO D, GIBSON E: Comparative safety of atorvastatin $80 \mathrm{mg}$ versus $10 \mathrm{mg}$ derived from analysis of 49 completed trials in 14,236 patients. Am J Cardiol 97: 61-67, 2006.

NIEMI M, PASANEN MK, NEUVONEN PJ: SLCO1B1 polymorphism and sex affect the pharmacokinetics of pravastatin but not fluvastatin. Clin Pharmacol Ther 80: 356-366, 2006.

NIEMI M, PASANEN MK, NEUVONEN PJ: Organic anion transporting polypeptide 1B1: a genetically polymorphic transporter of major importance for hepatic drug uptake. Pharmacol Rev 63: 157-181, 2011.

OH J, BAN MR, MISKIE BA, POLLEX RL, HEGELE RA: Genetic determinants of statin intolerance. Lipids Health Dis 6: 7, 2007.

PARKER BA, AUGERI AL, CAPIZZI JA, BALLARD KD, TROYANOS C, BAGGISH AL, D'HEMECOURT PA, THOMPSON PD: Effect of statins on creatine kinase levels before and after a marathon run. Am J Cardiol 109: 282-287, 2012.

PARKER BA, CAPIZZI JA, GRIMALDI AS, CLARKSON PM, COLE SM, KEADLE J, CHIPKIN S, PESCATELLO LS, SIMPSON K, WHITE CM, THOMPSON PD: Effect of statins on skeletal muscle function. Circulation 127: 96-103, 2013.

PASANEN MK, NEUVONEN M, NEUVONEN PJ, NIEMI M: SLCO1B1 polymorphism markedly affects the pharmacokinetics of simvastatin acid. Pharmacogenet Genomics 16: 873-879, 2006.

PASANEN MK, FREDRIKSON H, NEUVONEN PJ, NIEMI M: Different effects of SLCO1B1 polymorphism on the pharmacokinetics of atorvastatin and rosuvastatin. Clin Pharmacol Ther 82: 726-733, 2007.

PASANEN MK, MIETTINEN TA, GYLLING H, NEUVONEN PJ, NIEMI M: Polymorphism of the hepatic influx transporter organic anion transporting polypeptide 1B1 is associated with increased cholesterol synthesis rate. Pharmacogenet Genomics 18: 921-926, 2008.

PREMRU V, KOVAČ J, PONIKVAR R: Use of myoglobin as a marker and predictor in myoglobinuric acute kidney injury. Ther Apher Dial 17: 391-395, 2013.

RAJU SB, VARGHESE K, MADHU K: Management of statin intolerance. Indian J Endocrinol Metab 17: 977-982, 2013.

ROBINSON MR, WRAY NR, VISSCHER PM: Explaining additional genetic variantion in complex traits. Trends Genet 30: 124-132, 2014.

SEARCH COLLABORATIVE GROUP, LINK E, PARISH S, ARMITAGE J, BOWMAN L, HEATH S, MATSUDA F, GUT I, LATHROP M, COLLINS R: SLCO1B1 variants and statin-induced myopathy - a genomewide study. N Engl J Med 359: 789-799, 2008.

SEMPLE SJ: Statin therapy, myopathy and exercise - a case report. Lipids Health Dis 11: 40, 2012.

STEWART A: SLCO1B1 polymorphisms and statin-indused myopathy. PloS Curr Evidence on Genomic Tests 1: doi: 10.1371/currents.eogt.d21e7f0c58463571bb0d9d3a19b82203, 2013.

VOORA D, SHAH SH, SPASOJEVIC I, ALI S, REED CR, SALISBURY BA, GINSBURG GS: The SLCO1B1*5 genetic variant is associated with statin-induced side effects. J Am Coll Cardiol 54: 1609-1616, 2009.

YOUNG JM, FLORKOWSKI CM, MOLYNEUX SL, MCEWAN RG, FRAMPTON CM, GEORGE PM, SCOTT RS: Effect of coenzyme Q (10) supplementation on simvastatin-induced myalgia. Am J Cardiol 100: 1400-1403, 2007.

ZLATOHLAVEK L, VRABLIK M, GRAUOVA B, MOTYKOVA E, CESKA R: The effect of coenzyme Q10 in statin myopathy. Neuro Endocrinol Lett 33 (Suppl 2): 98-101, 2012.

ZUCCARO P, MOMBELLI G, CALABRESI L, BALDASSARE D, PALMI I, SIRTORI CR: Tolerability of statins is not linked to CYP450 polymorphisms, but reduced CYP2D6 metabolism improves cholesteraemic response to simvastatin and fluvastatin. Pharmacol Res 55: 310-317, 2007. 